\title{
DC Conduction and Switching Mechanisms in Electroformed Al/ZnTe:V/Cu Devices at Atmospheric Pressure
}

\author{
M. S. Hossain, ${ }^{1}$ R. Islam, ${ }^{2}$ and K. A. Khan ${ }^{2}$ \\ ${ }^{1}$ Department of Physics, Rajshahi University of Engineering \& Technology, Rajshahi 6204, Bangladesh \\ ${ }^{2}$ Department of Applied Physics and Electronic Engineering, University of Rajshahi, Rajshahi 6205, Bangladesh
}

Correspondence should be addressed to M. S. Hossain, sazzad_phy@yahoo.com

Received 27 March 2011; Accepted 17 April 2011

Academic Editor: B. Luan

Copyright ( $) 2011$ M. S. Hossain et al. This is an open access article distributed under the Creative Commons Attribution License, which permits unrestricted use, distribution, and reproduction in any medium, provided the original work is properly cited.

\begin{abstract}
Vanadium-doped zinc telluride (ZnTe:V) thin film sandwiched by two different metal electrodes, that is, $\mathrm{Al} / \mathrm{ZnTe}: \mathrm{V} / \mathrm{Cu}$ structure, was deposited onto the glass substrate by e-beam deposition technique in vacuum at a pressure of $\sim 8 \times 10^{-4} \mathrm{~Pa}$. The deposition rate of the film was maintained at $2.052 \mathrm{nms}^{-1}$. Circulation current was measured through this device as a function of potential difference applied across the structure. The $\mathrm{Al} / \mathrm{ZnTe}: \mathrm{V} / \mathrm{Cu}$ structures exhibit memory switching characteristics at atmospheric pressure in room temperature. Switching characteristics of deposited $\mathrm{Al} / \mathrm{ZnTe}: \mathrm{V} / \mathrm{Cu}$ structure as a memory device have been investigated in detail for various vanadium compositions, thicknesses of $\mathrm{ZnTe}: \mathrm{V}$ films as well as various film temperatures, respectively. In all cases, it is seen that the metal/insulator/metal $(\mathrm{Al} / \mathrm{ZnTe}: \mathrm{V} / \mathrm{Cu})$ structures based on $\mathrm{ZnTe}: \mathrm{V}$ can undergo an electroforming process and exhibit voltage-controlled negative resistance (VCNR) or a new switching process. It is also observed that the electric field, temperature, thickness, and dopant composition have important role in the switching characteristics. Switching characteristics have been interpreted by using a filamentary model. The switching effects of Al/ZnTe:V/Cu device may have important applications in the energy-oriented devices.
\end{abstract}

\section{Introduction}

Recently, materials of memory switching phenomena have been growing interest of many scientific and industrial research groups throughout the world. Zinc telluride ( $\mathrm{ZnTe})$ is such a compound semiconductor material of II-VI family that shows memory switching phenomena [1-3]. It is a low cost and usually p-type material and has a direct band gap of 2.2 to $2.3 \mathrm{eV}$ at room temperature.

The electrical and switching properties of sandwiched thin ZnTe films have been reported by several researchers [2-6]. All published reports are on metal/ZnTe/metal sandwich devices. S. M. Patel and N. G. Patel [4] have reported switching phenomena by using a coplanar Al-ZnTe-Al structure.

Ziari et al. have reported [7] that ZnTe exhibits improved photorefractive response when it is doped with vanadium $(\mathrm{ZnTe}: \mathrm{V})$. Vanadium is believed to be a deep donor in $\mathrm{ZnTe}$, and it has attractive use in a variety of applications including optical power limiting, optical computing, and optical communication. Kreissl et al. [8] have reported on electron paramagnetic resonance of vanadium-centered $\mathrm{ZnTe}$ crystals. No reports have been appeared on ZnTe:V thin films sandwiched by metal electrodes.

The electrical properties of sandwiched metal/ZnTe: $\mathrm{V} /$ metal have been studied in detail by the author. Nonlinear increase of conduction as a function of applied voltage is seen through the e-beam evaporated $\mathrm{Al} / \mathrm{ZnTe}: \mathrm{V} / \mathrm{Al}$ structure that has already been reported [9]. No switching phenomena are observed in $\mathrm{Al} / \mathrm{ZnTe}: \mathrm{V} / \mathrm{Al}$ structure. It is very interesting to note that when $\mathrm{ZnTe}: \mathrm{V}$ film is sandwiched by dissimilar metal electrodes, that is, $\mathrm{Al} / \mathrm{ZnTe}: \mathrm{V} / \mathrm{Cu}$ structure, then it shows switching characteristics. This structure is called formed device. Hence, there is a need to systematically study the dc conduction and switching mechanism through $\mathrm{Al} / \mathrm{ZnTe}: \mathrm{V} / \mathrm{Cu}$ formed devices to assess its usefulness in a variety of electronic devices. In this paper, we discussed the preparation of $\mathrm{Al} / \mathrm{ZnTe}: \mathrm{V} / \mathrm{Cu} \mathrm{M} / \mathrm{I} / \mathrm{M}$ structures and $\mathrm{dc}$ 
conduction including switching mechanism through these devices for various vanadium compositions, film thicknesses as well as for film temperatures, respectively.

\section{Experimental}

Vanadium-doped zinc telluride (ZnTe:V) mixture (containing 2.5 to $10 \mathrm{wt} \% \mathrm{~V}$ ) was produced from a $\mathrm{ZnTe}$ powder (99.999\% pure) and vanadium powder (99.999\% pure), respectively, obtained from Aldrich Chemical Company, USA. ZnTe:V thin films of thickness 100, 150, and $200 \mathrm{~nm}$ have been produced onto glass substrate by electron beam bombardment technique in vacuum at a pressure of $\sim 8 \times 10^{-4} \mathrm{~Pa}$. The deposition rate of the film was of $2.05 \mathrm{nms}^{-1}$. Each material was weighed by an electrical balance (Mettler TOLEDO, AB 204) having a resolution of $\pm 0.0001 \mathrm{~g}$, according to percentage composition to be used. The percentage composition of starting materials in the evaporant mixture was determined as in the study by Khan [10],

$$
\text { Weight } \% \mathrm{~V}=\frac{W_{\mathrm{V}}}{W_{\mathrm{V}}+W_{\mathrm{ZnTe}}} \times 100 \%
$$

where $W_{\mathrm{V}}$ and $W_{\mathrm{ZnTe}}$ are the weights of vanadium $(\mathrm{V})$ and zinc telluride ( $\mathrm{ZnTe})$, respectively. When the chamber pressure reduced to $\sim 8 \times 10^{-4} \mathrm{~Pa}$, deposition was then started with beam current of $40-50 \mathrm{~mA}$ by turning on the low-tension control switch of the electron beam supply (EBS) unit. The lower $\mathrm{Al}$ (Aluminum) and upper $\mathrm{Cu}$ (Copper) electrodes were evaporated during the same pump down cycle. Three masks (one for ZnTe:V films and other two for electrodes) were used for deposition of sandwich devices. All the films were deposited at room temperature. The film thickness was measured by the Tolansky [11] interference method with an accuracy of $\pm 5 \mathrm{~nm}$. The sandwich $\mathrm{Al} / \mathrm{ZnTe}: \mathrm{V} / \mathrm{Cu}(\mathrm{M} / \mathrm{I} / \mathrm{M}$ based) structure for measuring $I-$ $V$ characteristics at various conditions and its schematic diagram is shown in Figure 1.

$I$ - $V$ characteristics of sandwich $\mathrm{Al} / \mathrm{ZnTe}: \mathrm{V} / \mathrm{Cu}$ structures were measured as a function of temperature in the 300 to $340 \mathrm{~K}$ ranges. A dc power supply (KENWOOD, model: TMI6030050) was used to pass a constant dc current through the test sample. An electrometer (Keithley, Model: 614) monitored the current through the sample and a digital multimeter (Model: DM-206) was used to measure the potential differences across each sample. Sometimes, the analog multimeter (model: WV-38A) was used instead of electrometer in the circuit to monitor the sharp switching behavior of circulating current. DC bias voltage across the structure is increased slowly maintaining a regular time interval so that the increasing current reaches its steady value. This method is repeated until a sharp increase in the circulating current at a particular voltage initiates the forming process. The procedure is adopted to further increase the bias potential difference across the structure until the peak current drops suddenly to its minimum value and again increased to monitor the current.

The structure of ZnTe: $\mathrm{V}$ thin films of various compositions (2.5 to $10 \mathrm{wt} \% \mathrm{~V})$ and thicknesses (100 to $200 \mathrm{~nm}$ ) for

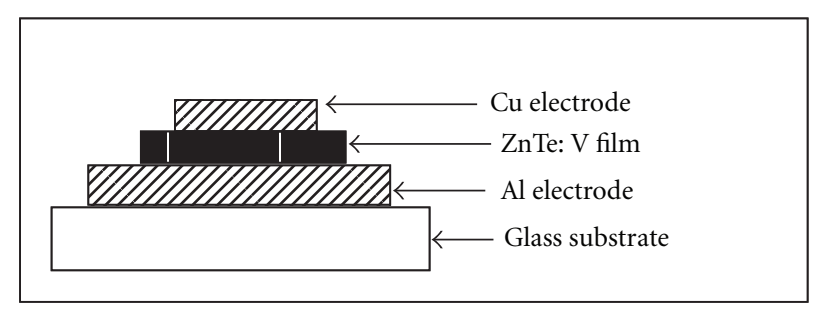

FIGURE 1: Schematic diagram of sandwich Al/ZnTe:V/Cu based $\mathrm{M} / \mathrm{I} / \mathrm{M}$ structure.

both as-deposited and annealed films were examined by Xray diffraction (XRD) technique using the monochromatic $\mathrm{CuK} \alpha$ radiation made by an apparatus, RINT 2200, Rigaku, Japan. Peak intensities were recorded corresponding to $2 \theta$ values. The X-ray data reveals that the author's ebeam deposited ZnTe:V thin films are mixed crystalline in structure.

\section{Results and Discussion}

It is well known that a metal/insulator/metal (M/I/M) sandwich structure can undergo a forming process under certain conditions, during which the electrical conductivity of the sample increases by several orders of magnitude [12]. This process is known as electroforming. Author's sandwich $\mathrm{Al} / \mathrm{ZnTe}: \mathrm{V} / \mathrm{Cu}$ structure of dissimilar metal electrodes shows this type of forming, and it is called formed device. The forming process depends on ambient pressure, temperature, electric field, thickness, and work functions of used electrode materials. Here, it is very interesting to note that the author's samples show forming process at room temperature in atmospheric pressure.

Figure 2 illustrates the $I-V$ curve for a $150 \mathrm{~nm}$ thick $\mathrm{Al} / \mathrm{ZnTe}: \mathrm{V} / \mathrm{Cu}$ electroformed structures of compositions (2.5 to $10 \mathrm{wt} \% \mathrm{~V}$ ) at normal atmospheric pressure and room temperature, showing voltage-controlled negative resistance (VCNR) regions. In the VCNR regions, the circulating current $\left(I_{C}\right)$ is decreased as the sample voltage is increased. $I-V$ graphs may be divided in to three regions, such as threshold $\left(V_{T}\right)$, forming $\left(V_{F}\right)$ at peak circulating current $\left(I_{P}\right)$, and the valley $\left(V_{V}\right)$ voltage, respectively. It is seen that, on increasing the bias voltage of the formed devices beyond the forming voltage $V_{F}(0.7$ to $2.5 \mathrm{~V})$ in Figure 2, an abrupt change in the electrical characteristics was found. The peak current of the formed device was found to decrease by several orders of magnitude by a continuous process. This behavior may be called switching. Switching may be of two types: the normal switching and the other is N-type switching. In the normal switching, on increasing the bias potential beyond $V_{F}$, the current suddenly dropped to a minimum value. In the second one, circulating current increases to steady value, and beyond $V_{F}$ the current reaches a minimum value and then increases again with increasing bias potential. This type of switching is called N-type. It is noted from Figure 2 that the author's formed structure shows a sharp normal switching and it sometimes exhibits an N-type switching. 


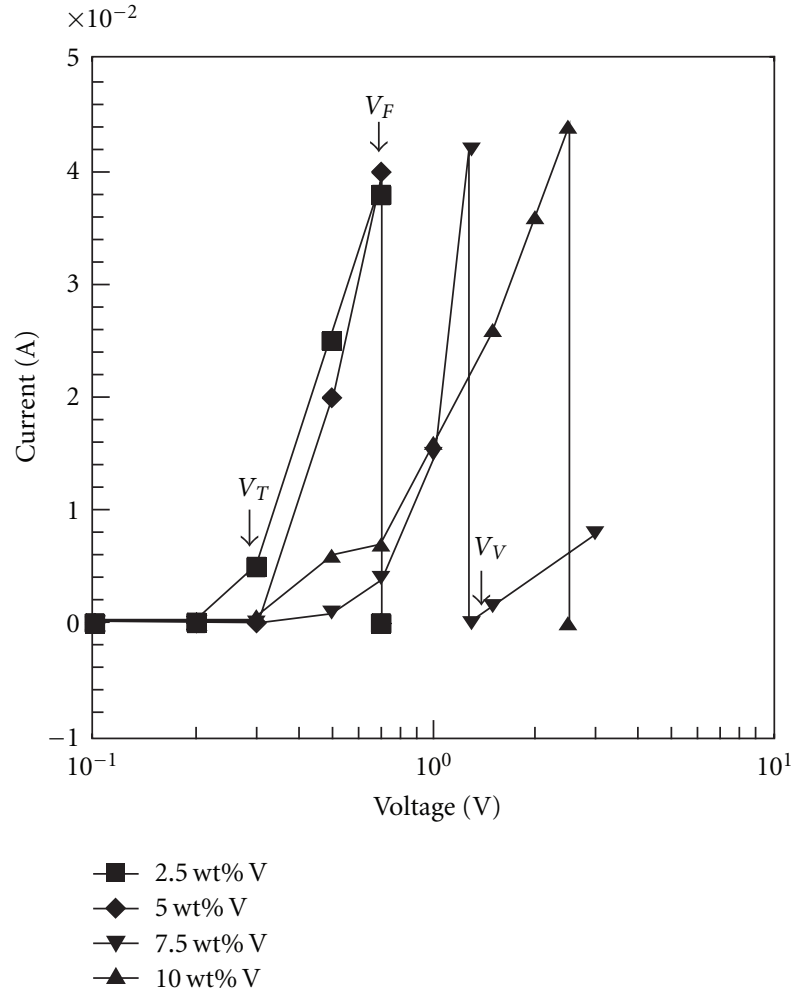

Figure 2: $I-V$ curves for a $150 \mathrm{~nm}$ thickness of $\mathrm{Al} / \mathrm{ZnTe}: \mathrm{V} / \mathrm{Cu}$ structure at different compositions: ( $\boldsymbol{\square}$ ) 2.5, ( $)$ 5.0, ( $\mathbf{\nabla}$ ) 7.5, and (ム) $10 \mathrm{wt} \% \mathrm{~V}$.

Initially, the entire author's sample of $\mathrm{Al} / \mathrm{ZnTe}: \mathrm{V} / \mathrm{Cu}$ sandwich structures was in OFF state, and it has shown nonlinear $I-V$ characteristics up to $V_{T}$. When the bias voltage exceeds the threshold voltage $\left(V_{T}\right)$, the structure switches to the ON state which is shown as ohmic behavior. The device could be switched back to the OFF state instantly after reaching peak current $\left(I_{P}\right)$. Since both states are restored after removal of the bias voltage, these devices may behave as a memory switch. The ratio of OFF state resistance $R_{\mathrm{OFF}}$ to the ON state resistance $R_{\mathrm{ON}}$ is about $10^{4}$. Similar OFF $\leftrightarrow \mathrm{ON}$ and memory switching behavior has also been reported in a coplanar Al-ZnTe-Al device by S. M. Patel and N. G. Patel [4]. The OFF $\rightarrow$ ON transition may be accompanied by the formation of a filament which bridges the electrodes. The probable reasons behind the switching back to the OFF state or $\mathrm{ON} \rightarrow$ OFF state may be associated with rupture of filament and the formation of tellurium islands resulting from melting followed by rapid cooling and solidification of ruptured filaments [4]. The formation of Tellurium Island in the ruptured filaments breaks the continuity between electrodes, and hence the OFF state is regained. It is also observed from Figure 2 that the value of peak circulating current is increased with increasing the vanadium content in $\mathrm{ZnTe}$ matrix. The threshold voltage $\left(V_{T}\right)$ and forming voltage $\left(V_{F}\right)$, respectively, were found to shift towards a high value with increasing vanadium concentration.

Figure 3 shows the thickness effect of a 100, 150, and $200 \mathrm{~nm}$ thick $\mathrm{Al} / \mathrm{ZnTe}: \mathrm{V} / \mathrm{Cu}$ structure at a particular

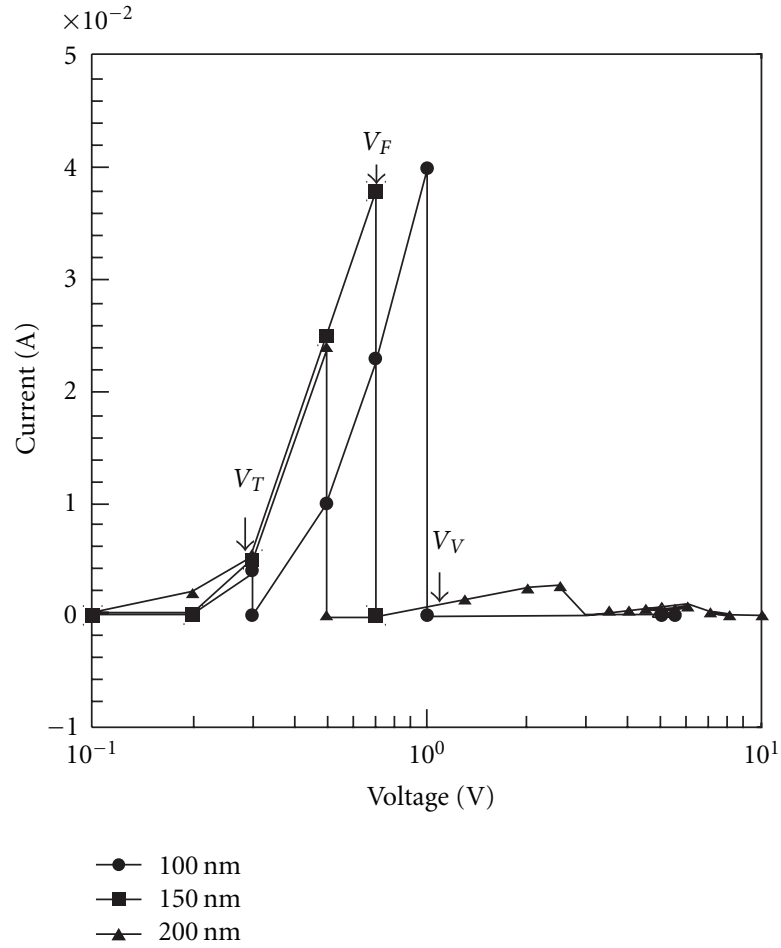

Figure 3: $I-V$ curves for $\mathrm{Al} / \mathrm{ZnTe}: \mathrm{V} / \mathrm{Cu}$ structure of composition $2.5 \mathrm{wt} \% \mathrm{~V}$ at different thickness: $(\bullet) 100 \mathrm{~nm},(\boldsymbol{\square}) 150 \mathrm{~nm}$, and $(\boldsymbol{\Delta})$ $200 \mathrm{~nm}$.

composition of $2.5 \mathrm{wt} \% \mathrm{~V}$, respectively. The M/I/M structure has pronounced effect on electroforming, and it shows VCNR regions with sharp switching. The forming voltage $\left(V_{F}\right)$ was found to lie between 1.0 and $0.5 \mathrm{~V}$, and the forming voltage $\left(V_{F}\right)$ is found to decrease with increasing film thickness. Similar decease in peak circulating current $\left(I_{P}\right)$ is observed with increasing film thickness. The decrease in $V_{F}$ with increasing film thickness may arise from the formation of large filamentary path or from the distorted filaments that are formed between electrodes.

Temperature also affects the electroforming or switching characteristics. In the investigated temperature range of 300 to $340 \mathrm{~K}$, the peak circulating current $\left(I_{P}\right)$ of the formed sample of a $150 \mathrm{~nm}$ thick $\mathrm{Al} / \mathrm{ZnTe}: \mathrm{V} / \mathrm{Cu}$ structure is shown in Figure 4. It is seen that the forming voltage $\left(V_{F}\right)$ was found to shift towards a low value with increasing temperature. At temperatures of 320 and $340 \mathrm{~K}$, the initial impedances may be decreased compared to the value at room temperature, and as a result the forming voltage $\left(V_{F}\right)$ shifts to a low value, while the peak current is shown to increase with increasing temperature.

To study the aging effect on switching, a freshly prepared formed $\mathrm{Al} / \mathrm{ZnTe}: \mathrm{V} / \mathrm{Cu}(2.5 \mathrm{wt} \% \mathrm{~V}, 150 \mathrm{~nm})$ sample is stored in desiccators in air (at atmospheric pressure) for a period of 1 week. Figure 5 illustrates that the switching mechanism is still exhibited to occur. The forming voltage of an aged sample is higher $(>0.7 \mathrm{~V})$ than the voltage required for a virgin (original) sample. The forming voltage on an aged sample is seen to shift to higher applied voltage with aging. 
TABLE 1: The corresponding values of the coefficients of $a_{n}$ with order number.

\begin{tabular}{|c|c|c|c|c|c|c|}
\hline Order $(n)$ & $a_{0}$ & $a_{1}$ & $a_{2}$ & $a_{3}$ & $a_{4}$ & Error \\
\hline 2 & $-5.28 \times 10^{-3}$ & $2.64 \times 10^{-2}$ & $5.33 \times 10^{-2}$ & & & $3.91 \times 10^{-3}$ \\
\hline 3 & $1.24 \times 10^{-2}$ & $-1.97 \times 10^{-1}$ & $8.46 \times 10^{-1}$ & $-9.87 \times 10^{-1}$ & & $9.39 \times 10^{-4}$ \\
\hline 4 & $4.49 \times 10^{-3}$ & $-6.27 \times 10^{-2}$ & $1.47 \times 10^{-1}$ & $3.85 \times 10^{-1}$ & $-5.27 \times 10^{-1}$ & $1.00 \times 10^{-4}$ \\
\hline
\end{tabular}

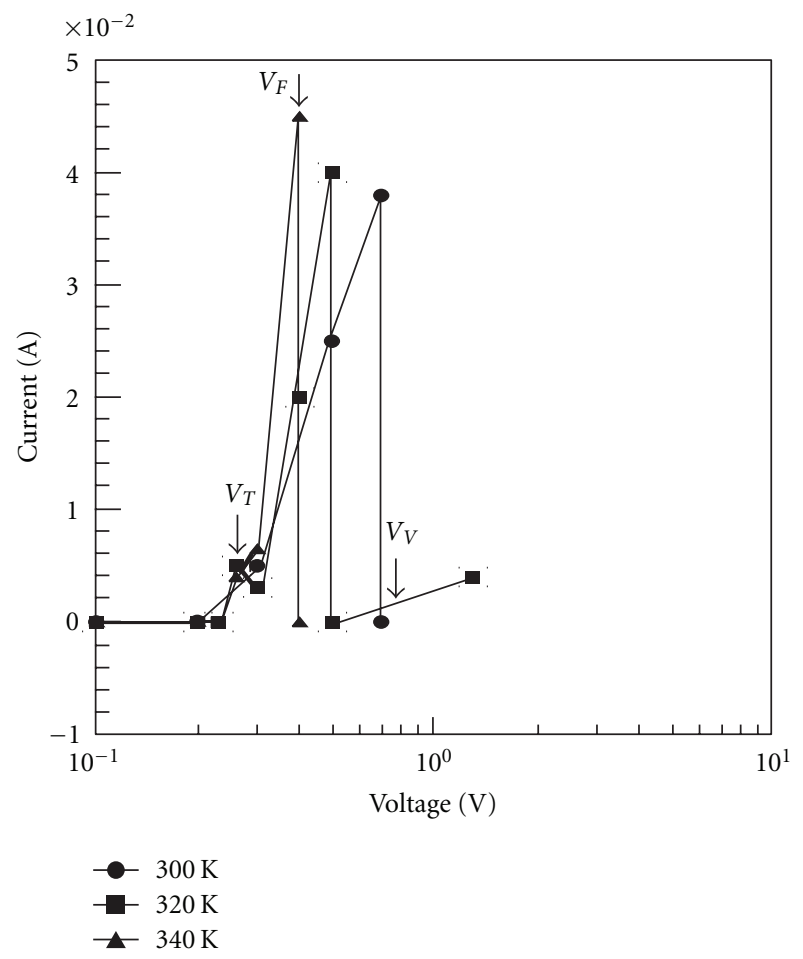

Figure 4: $I-V$ curves for a $150 \mathrm{~nm} \mathrm{Al/ZnTe:V/Cu} \mathrm{structure} \mathrm{at}$ $2.5 \mathrm{wt} \% \mathrm{~V}$ at different temperatures: $(\bullet) 300 \mathrm{~K},(\boldsymbol{\square}) 320 \mathrm{~K}$ and $(\mathbf{\Delta})$ $340 \mathrm{~K}$.

It is also found that the peak circulating current $\left(I_{P}\right)$ of the aged sample is comparatively lower during the voltage cycling than that of the original sample. This type of switching is reversible in nature. It is thought that storing at atmospheric pressure may cause oxygen to be incorporated with the film resulting in higher initial impedance and inhibiting process. Thus, the overall impedance of the sample is increased resulting in a substantial drop in current and slight decrease in the forming voltage during the voltage cycling. This may be explained due to an effect of oxygen atmosphere on the film. It is believed that electroforming is a consequence of structural change occurring in the present films. Conduction after electroforming is explicable by considering the formation and rapture of conducting filaments through the film during the voltage cycling as a result of Joule heating [13].

Figure 6 shows the $I-V$ curve of the formed Al/ZnTe: $\mathrm{V} / \mathrm{Cu}$ devices for a thick $150 \mathrm{~nm}$ of composition $2.5 \mathrm{wt} \% \mathrm{~V}$. From the figures, switching behavior is observed in increasing bias voltage cycle, and it is absent in the immediate

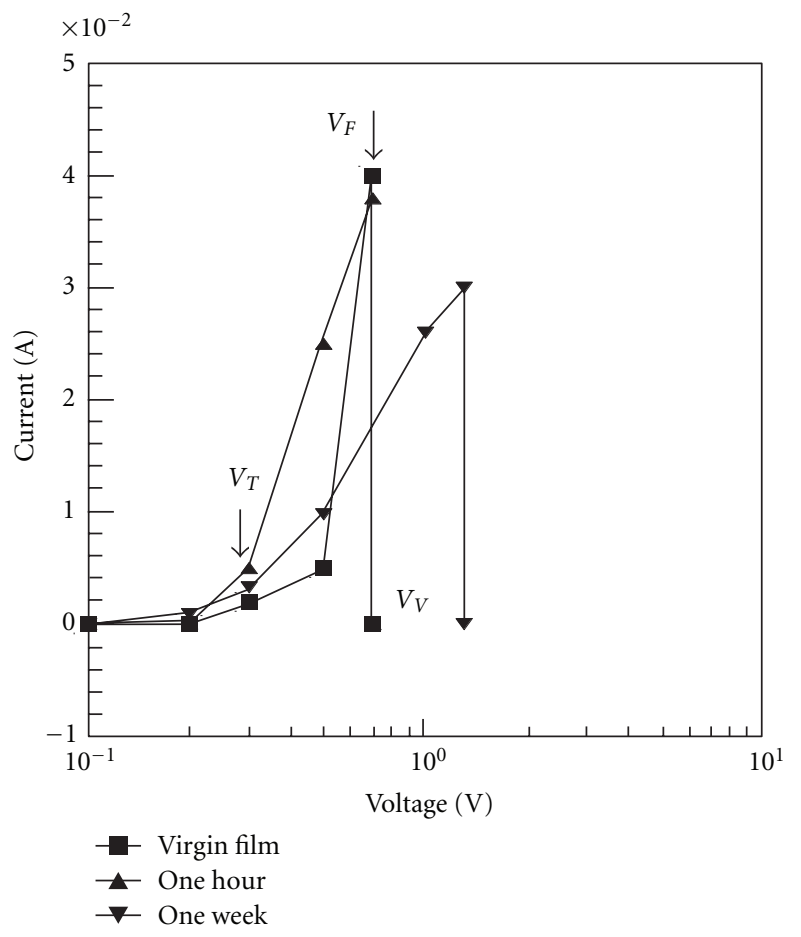

Figure 5: $I-V$ aging effects for a $150 \mathrm{~nm}$ thick $\mathrm{Al} / \mathrm{ZnTe}: \mathrm{V} / \mathrm{Cu}$ structure of a composition $2.5 \mathrm{wt} \% \mathrm{~V}$ : ( $\boldsymbol{\square})$ virgin film, ( $\boldsymbol{\Delta})$ one hour, and $(\boldsymbol{\nabla})$ one week.

decreasing voltage cycle. This means that the forming devices are reversible but not reproducible.

Explanation of switching: From Figure 6, at low bias voltage, conduction (in $\mathrm{AB}$ region) is seemed to be nonohmic behaviour; filaments may be nonuniform in cross-section of the devices, at higher voltage ( $\mathrm{BC} \& \mathrm{CD}$ regions), as the filaments are unlikely to be perfectly uniform in crosssection; that is, weak spots are present. Normal switching covers the region BCD. The dc current will not flow through the capacitor $C_{p}$ as shown in Figure 7. The usual path of dc current is through $R_{p}$ and $R_{S}$ called filamentary path for $B C$ region, and arises from structural changes of the $\mathrm{ZnTe}: \mathrm{V}$ films, diffusion of $\mathrm{Cu}$ from the electrode, and the presence of vanadium in ZnTe matrix. With an increase of the bias voltage, more electrons will flow through this path, and Joule heating increases. As a result the weak spots of the filament will rupture with an accelerating decrease of current, and this is the cause of catastrophic breakdown (in CD region) with showing VCNR region. In N-type switching, an increase in the bias voltage caused the current to reach a minimum value and then to increase again as shown in Figure 2 for 


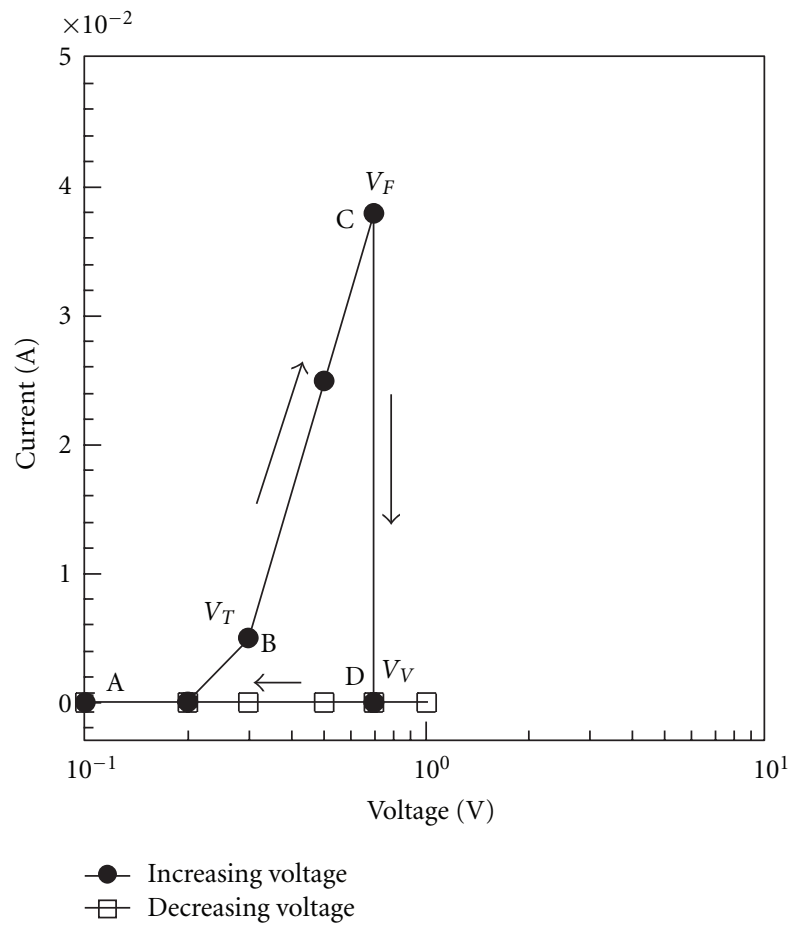

Figure 6: Reversible phenomena in electroformed $\mathrm{Al} / \mathrm{ZnTe}: \mathrm{V} / \mathrm{Cu}$ devices at room temperature: $(\bullet)$ increasing voltage and $(\square)$ decreasing voltage.

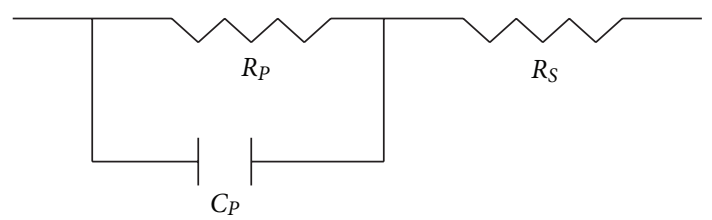

Figure 7: Probable electronic circuit diagram of the $M / I / M$ structure.

$7.5 \mathrm{wt} \% \mathrm{~V}$, Figure 3 for the thickness of $200 \mathrm{~nm}$, respectively, as observed in planar discontinuous metal films [14]. The regions of $\mathrm{BC}, \mathrm{CD}$ may be explained similarly but beyond this region as in Figure 2 may be explained by introducing the concept of trapping centers. As the present investigated films are amorphous in nature, it is more probable that these contain a large density of trapping centers. From the theory of the defect insulator [15], as the bias voltage is increased further, a greater current is produced and flows through the device. In consequence, a higher proportion of traps become filled. Thus the current density increases again along after CD region. The filamentary and trap concept of other workers [16-18] offers an explanation of the entire N-type switching phenomena.

In various filamentary models, Ray and Hogarth [16], Dearnaley et al. [19], Rakhshani et al. [20], and Li and Beynon [21] state that filamentary current conducting paths are established between the metal electrodes when a sufficient voltage is applied across the film. After forming, conduction

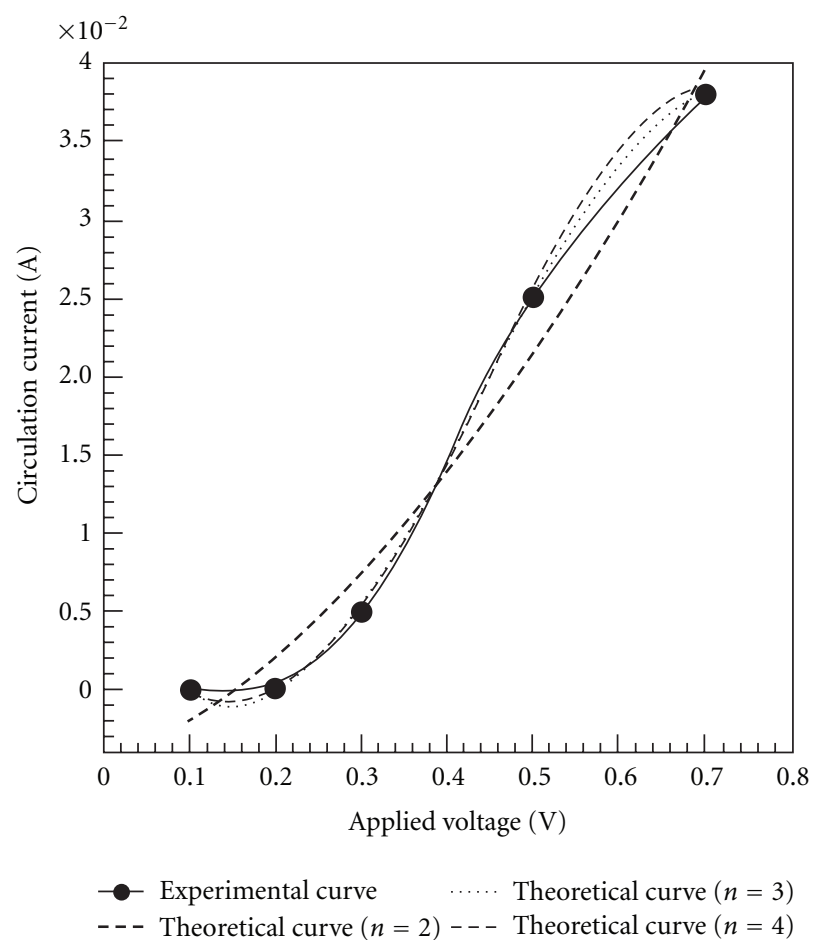

Figure 8: $I-V$ curves fitting based on polyfilamentary model: $(\bullet)$ experimental curve; $(---)$ theoretical curve, $n=2 ;(\cdots)$ theoretical curve, $n=3$; (--) theoretical curve, $n=4$.

occurs with the help of these filaments, and hence the conducting level increases.

The interpretation of all the experimental results on formed devices is discussed in the light of a ploy-filamentary model by Ray and Hogarth [16]. In this model the circulating current $\left(I_{C}\right)$ through a formed sample is expressed as a polynomial in potential difference $\mathrm{V}$, by the following:

$$
I_{C}(\mathrm{~V})=\Sigma a_{n} \mathrm{~V}^{n}
$$

where $n$ is the zero or an integer and $a_{n}$ is a coefficient. Based on the filamentary model, author's results of a $150 \mathrm{~nm}$ thick $\mathrm{Al} / \mathrm{ZnTe}: \mathrm{V} / \mathrm{Cu}$ formed device of composition $2.5 \mathrm{wt} \% \mathrm{~V}$ are fitted for $n=2,3$, and 4, respectively, and the obtained fitted curves are shown in Figure 8. The corresponding values of the coefficients of $a_{n}$ are presented in Table 1 . Here, the best fit curve was obtained for $n=3$ from the figure.

\section{Conclusion}

$\mathrm{Al} / \mathrm{ZnTe}: \mathrm{V} / \mathrm{Cu}$ structure was deposited onto the glass substrate by e-beam deposition technique in vacuum at a pressure of $\sim 8 \times 10^{-4} \mathrm{~Pa}$. The deposition rate of the film was maintained at $2.052 \mathrm{nms}^{-1}$. The study of author's sample signifies the presence of a peak current and a sharp switching. The Al/ZnTe:V/Cu structures are exhibited memory switching characteristics at atmospheric pressure in room temperature. Switching characteristics of $\mathrm{Al} / \mathrm{ZnTe}: \mathrm{V} / \mathrm{Cu}$ structures as a memory device have been investigated for various vanadium compositions, thicknesses of $\mathrm{ZnTe}: \mathrm{V}$ films as well 
as various film temperatures, respectively. It is observed that the electric field, temperature, thickness, and dopant composition have important role in the switching characteristics. Switching characteristics have been interpreted by using a filamentary model. This study may therefore be of importance in regards to its energy-oriented device application such as solar cells.

\section{Acknowledgment}

One of the authors, M. S. Hossain, is indebted to Rajshahi University of Engineering \& Technology, Bangladesh for providing the study leave during this work.

\section{References}

[1] J. Tauc, Amorphous and Liquid Semiconductors, Plenum Press, New York, NY, USA, 1974.

[2] M. Burgelmen, "A ZnTe thin film memory device," Electrocomponent Science and Technology, vol. 7, p. 93, 1980.

[3] T. Ota and K. Takahashi, "Non-polarized memory-switching characteristics of ZnTe thin films," Solid State Electronics, vol. 16, no. 10, p. 1089, 1973.

[4] S. M. Patel and N. G. Patel, "Switching mechanism in ZnTe films," Thin Solid Films, vol. 113, no. 3, pp. 185-188, 1984.

[5] T. Shirakawa, A. Hayashi, and J. Nakai, "Space-charge-limitedcurrent in vacuum deposited ZnTe films," Japanese Journal of Applied Physics, vol. 9, p. 420, 1970.

[6] D. B. Holt and A. R. Mufti, "Irreversible switching of conductivity states in ZnTe/Ge heterojunctions," Solid State Electronics, vol. 16, no. 10, p. 1213, 1973.

[7] M. Ziari, W. H. Steier, P. M. Ranon, S. Trivedi, and M. B. Klein, "Photorefractivity in vanadium-doped ZnTe," Applied Physics Letters, vol. 60, no. 9, pp. 1052-1054, 1992.

[8] J. Kreissl, K. Irmscher, P. Peka, M. U. Lehr, H. J. Schulz, and U. W. Pohl, "Vanadium centers in ZnTe crystals. II. Electron paramagnetic resonance," Physical Review B, vol. 53, no. 4, pp. 1917-1926, 1996.

[9] M. S. Hossain, R. Islam, and K. A. Khan, "Temperature effect on the electrical properties of undoped and vanadium-doped ZnTe thin films," Renewable Energy, vol. 33, no. 4, pp. 642-647, 2008.

[10] A. S. Khan, Electrical, optical and micro-structural properties of Ag-Al2O3 cermet thin films for solar energy applications, Ph.D. thesis, University of Rajshahi, Bangladesh, 1999.

[11] S. Tolansky, Multiple Beam Interferometry of Surfaces and Films, Oxford University Press, London, UK, 1948.

[12] R. R. Verderber, J. G. Simmons, and B. Eales, "Forming process in evaporated SiO thin films," Philosophical Magazine, vol. 16, p. 1049, 1967.

[13] G. Dearnaley, A. M. Stoneham, and D. V. Morgan, "Electrical phenomena in amorphous oxide films," Reports on Progress in Physics, vol. 33, no. 3, article 306, pp. 1129-1191, 1970.

[14] P. Borziak, V. Dyukov, A. Kostenko, YU. Kulyupin, and S. Nepijko, "Electrical conductivity in structurally inhomogeneous discontinuous metal films," Thin Solid Films, vol. 36, no. 1, pp. 21-24, 1976.

[15] A. Rose, "Space-charge-limited currents in solids," Physical Review, vol. 97, no. 6, pp. 1538-1544, 1955.

[16] A. K. Ray and C. A. Hogarth, "A critical review of the observed electrical properties of MIM devices showing VCNR," International Journal of Electronics, vol. 57, p. 1, 984.
[17] R. D. Gould and R. A. Collins, Solid State Electronics, vol. 14, p. 805,1971 .

[18] J. G. Simmons and R. R. Venderber, "New conduction and reversible phenomena in thin insulating films," Proceedings of the Royal Society A, vol. 301, no. 1464, pp. 77-102, 1967.

[19] G. Dearnaley, D. V. Morgan, and A. M. Stoneham, "A model for filament growth and switching in amorphous oxide films," Journal of Non-Crystalline Solids, vol. 4, pp. 593-612, 1970.

[20] A. E. Rakhshani, C. A. Hogarth, and A. A. Abidi, "Observations of local defects caused by electrical conduction through thin sandwich structures of AgSiO/BaOAg," Journal of NonCrystalline Solids, vol. 20, no. 1, pp. 25-42, 1976.

[21] J. Li and J. Beynon, "New interpretation of the I-V characteristics of electroformed thin film sandwich structures," Vacuum, vol. 42, no. 12, pp. 775-778, 1991. 

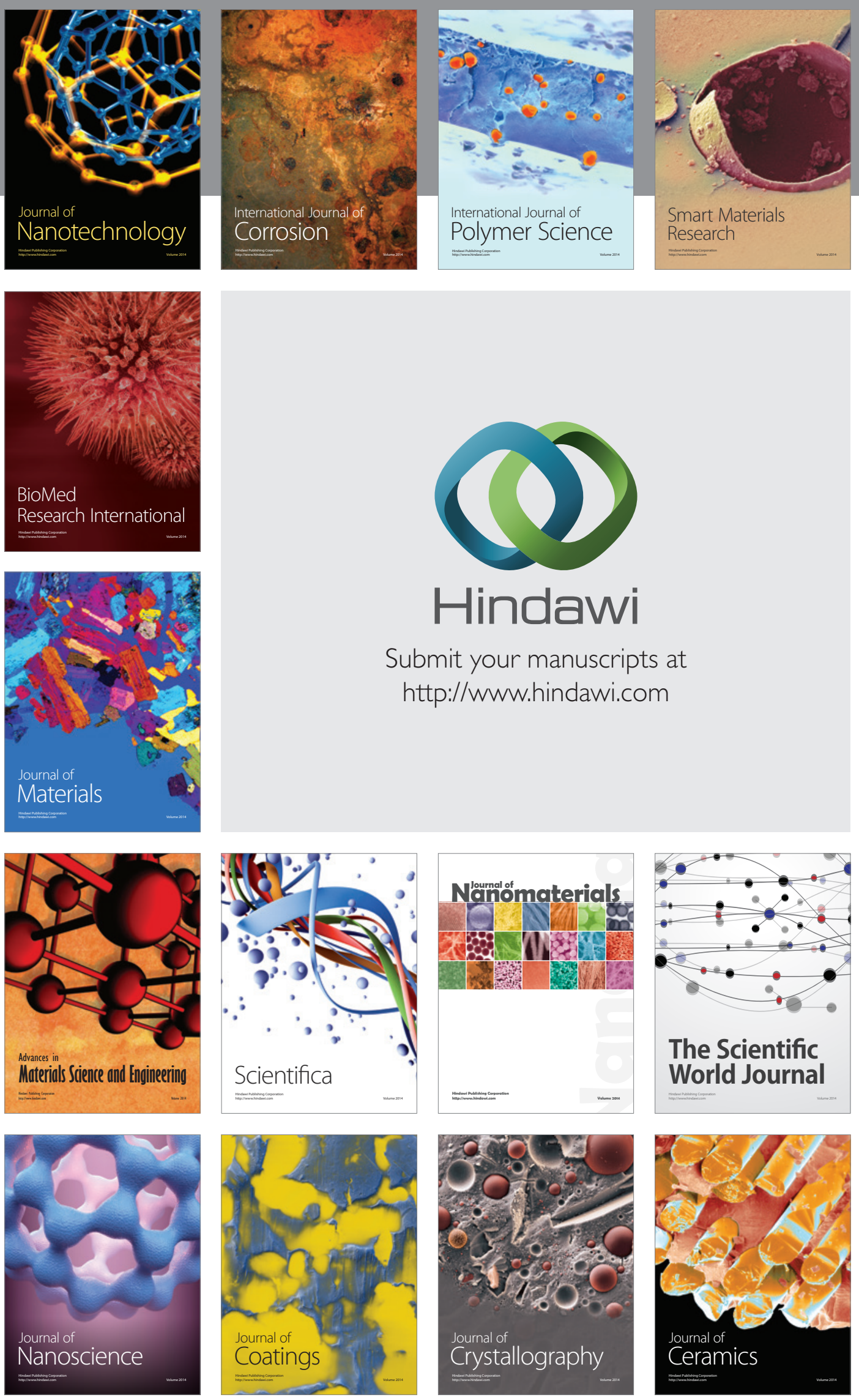

The Scientific World Journal

Submit your manuscripts at

http://www.hindawi.com

\section{World Journal}

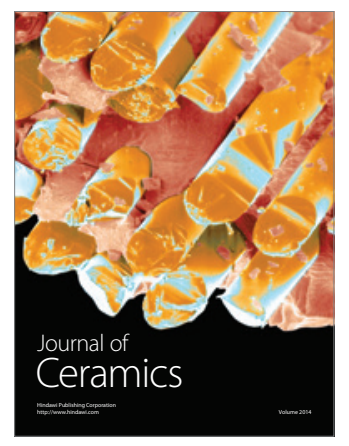

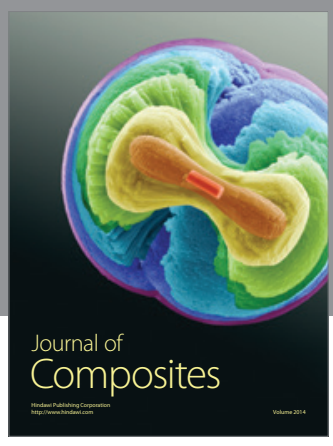
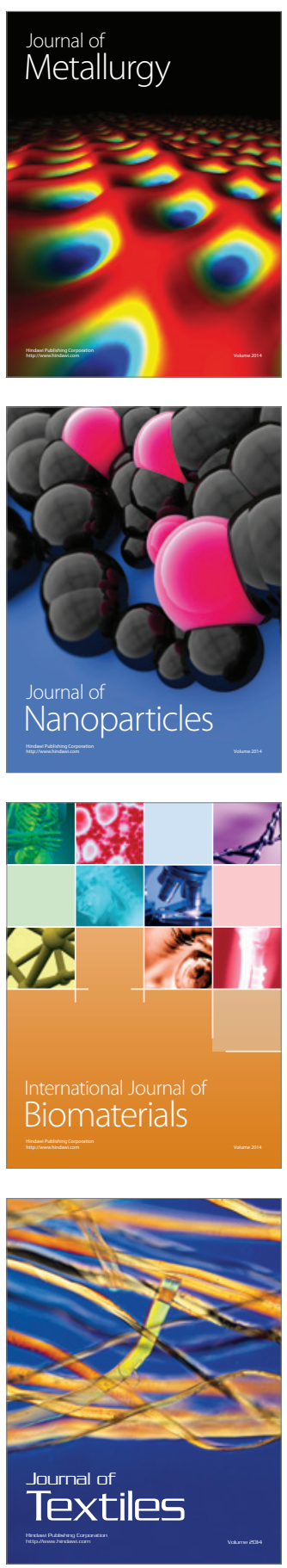